\title{
THE SUBJECTIVE WARRANT AND RECRUITMENT \\ INTO PHYSICAL EDUCATION
}

by

\section{ALISON MACKENZIE DEWAR}

B.Ed.(Hons.), Dunfermline College of Physical Education, Scotland, 1979

A THESIS SUBMITTED IN PARTIAL FULFILMENT

OF THE REQUIREMENTS FOR THE DEGREE OF

MASTER OF PHYSICAL EDUCATION

in

THE FACULTY OF GRADUATE STUDIES

(School of Physical Education and Recreation)

We accept this thesis as conforming

to the required standard

THE UNIVERSITY OF BRITISH COLUMBIA

June 1983

(C) Alison Mackenzie Dewar, 1983 
In presenting this thesis in partial fulfilment of the requirements for an advanced degree at the University of British Columbia, I agree that the Library shall make it freely available for reference and study. I further agree that permission for extensive copying of this thesis for scholarly purposes may be granted by the head of my department or by his or her representatives. It is understood that copying or publication of this thesis for financial gain shall not be allowed without my written permission.

Department of PHYSICAL EDUCATION AND RECREATION.

The University of British Columbia 1956 Main Mall

Vancouver, Canada

V6T $1 Y 3$

Date $2 / 8 / 83$ 
Table of Contents

Abstract

List of Tables

\section{CHAPTER ONE}

Introduction

Recruitment and professional socialization

Recruitment in a model for professional socialization

The subjective warrant and recruitment in physical education

Definition of terms

\section{CHAPTER TWO}

Literature review

The general literature on occupational choice

The professional socialization literature

Recruitment into the physical education profession

Implications of this research for the subjective warrant for physical education

Summary of the occupational choice research findings

\section{CHAPTER THREE}

The beginning of a theoretical framework

\section{CHAPTER FOUR}

Method

Subjects

Instrument

Procedure

Constraints

\section{CHAPTER FIVE}

Results and discussion

General background characteristics

Summary of general background characteristics 
in physical education 61

Summary of results $\quad 62$

\section{CHAPTER SIX}

Conclusions

Implications for further research

Bibliography

Appendix 


\section{ABSTRACT}

The purposes of this study were to review and synthesize a wide variety of occupational choice and professional socialization literature in order to develop and test a theoretical framework for the subjective warrant for physical education.

Forty subjects from six schools in the Vancouver School Board served as subjects for the study. There were six categories of subjects in this study, males and females who were decided on a career in physical education, who were attracted to a career in physical education and who were high achievers in sport and physical education but had decided against a career in physical education.

A written questionnaire, which was developed from the theoretical framework and pilot tested on both undergraduate physical education majors and grade 12 high school students, was administered to the subjects in small groups. The data from the study was analysed using content analysis and qualitative research methods.

It was found that for a majority of individuals there existed a dominant subjective warrant for physical education. This subjective warrant was one in which a career in physical education was viewed as a career in teaching and coaching. A small minority of subjects in the study had subjective warrants that did not view teaching and coaching as the only career opportunities available in physical education. In addition, it was found that the majority of subjects who had rejected careers in physical education had subjective warrants in which a career in physical education 
was viewed as a career in teaching and this view of the profession was cited as the primary reason for their rejection of a career in the profession.

In conclusion, the physical education profession is announcing itself to the majority of individuals in one way - as offering careers in teaching and coaching. This dominant perception of the profession serves to attract a majority of individuals oriented to careers in teaching but repels others who, although not oriented to teaching, may be equally well suited to alternative careers in physical education. 


\section{List of Tables}

\section{TABLE ONE}

The factors influencing an individual's subjective warrant for physical education

\section{TABLE TWO}

Predicted profiles of male and female physical education recruits

TABLE THREE

Number of subjects tested in each category by sex 
vii

\section{ACKNOWLEDGEMENT}

This thesis would not have been possible without the cooperation of the Vancouver School Board, the principals, physical education staff and students who volunteered as subjects for this study from Killareny, Kitsilano, Eric Harber, Lord Byng, Point Grey and Templeton secondary schools. To them I express my thanks.

Thanks to Dr. Gary Sinclair, Dr. Robert Morford and Mr. Jim Appleby for their encouragement and guidance during the writing of this thesis. Special thanks to Dr. Hal Lawson for all of his comments, guidance and encouragement without which the writing of this thesis would not have been possible. 
Those who cannot do, teach

Those who cannot teach,

teach gym.

Woody Allen in Annie Hall.

The survival of a profession is largely dependent upon its ability to recruit new members. In this light, it is difficult to understand why there has been so little conceptual and empirical attention paid in physical education to the process of recruitment, generally, and the choice of physical education specifically. Questions abound. For example, what is the image of the profession? How is this transmitted to potential recruits? What effect does this image have on recruitment? Questions such as these serve as a point of departure for the ensuing investigation.

\section{Recruitment and Professional Socialization}

Individuals, at some point in life have to make an occupational choice. This choice is one that is influenced by an interplay of personal, situational and societal factors. In an attempt to understand the ways in which an individual is attracted towards and inducted into an occupation, sociologists have linked the process of occupational choice with the concept of socialization.

Professional socialization represents one specific type of occupational socialization. It refers to the interaction and learning by means of which an individual acquires the ideological perspectives appropriate for a professional role, and the knowledge, skills and sensitivities that are essential for the performance of this role. 
In the past, some analysts have assumed that this process of professional socialization begins when an individual enters a programme of formal professional education. However, the process begins before this stage, commencing when the individual is attracted towards a particular profession, for learning about the culture of a profession appears to begin at this early stage.

It follows that professional socialization can be conceptualized as a process that spans an entire career, beginning when an individual is attracted to a profession, and continuing through formal education and entry into the workforce. This definition also provides one with a useful heuristic device for investigations of professional choice as it affords one with a framework in which attraction to a profession is viewed as the first of three stages of professional socialization. Knowledge about the dynamics of this choice is.crucial to an understanding of the whole process of professional socialization. That is, attraction to a profession is based upon an individual's perceptions of the profession, which, in turn, influence the extent to which the individual internalizes the culture of the profession.

\section{Recruitment in a Model for Professional Socialization}

Early studies of the medical and legal professions led to the development of a three stage model for professional socialization (Becker, 1961; Merton, 1957). Later studies of professional socialization in teaching (Lortie, 1975; Western and Anderson, 1968), and in the teaching of physical education (Pooley, 1970, 1975; Templin, 1979; Woodford, 1977) were guided by this model. 
The stages in the model represent three parts of the socialization process. Stage one is recruitment into the profession. Stage two comprises the formal education and training, that occurs in the universities, for the profession. Stage three is marked by entry into the workforce.

Within the framework provided by this model it is assumed that there are relationships between the three stages. Between stages one and two, recruitment into the profession and entry into programmes of formal education, it is assumed that there is discontinuity for the individual. That is, it is assumed that recruits have inaccurate, incomplete perceptions of the culture of the profession, and formal education makes this incongruity clear to them. This is one of the methods used to initiate induction of new recruits into the profession. The relationship between the last two stages of the model, formal education and entry into the workforce, is viewed as having a high degree of continuity for the individual. This is based on the assumption that there is a high degree of correspondence between an individual's knowledge, skills and expectations acquired during professional education, and the actual nature of the work and professional culture that exist in the workplace. It is this correspondence or continuity that marks successful socialization and induction into the profession.

This three stage model has been used to guide studies of professional socialization in teaching (Western and Anderson, 1968; Lortie, 1975). The focus of attention of these studies has, in the main, been on the second and third stages of the model. Much less attention has been afforded to the first stage of the model, recruitment into both teaching generally, and for physical education specifically. Yet, it is the recruitment stage of the 
socialization process that may provide the key to an understanding of the whole process. In other words, an understanding of the second stage of the model, socialization during professional education, is contingent upon an understanding of the factors influencing the first stage of the model, recruitment into the professions.

\section{The Subjective Warrant and Recruitment into Physical Education}

\section{Purpose of the Investigation}

What attracts individuals to a career in physical education? How does the profession announce itself to potential recruits? How do these recruits view the profession they have chosen to enter? These questions are directiy related to recruitment into the physical education profession. They are important questions that must be answered in order to derive an understanding of the effectiveness of professional education programmes as socializing agencies, and subsequently to ensure that these programmes are effective. They also have import for an understanding of the profession proper.

One purpose of this investigation is to develop a theoretical framework for the examination of one aspect of the recruitment process in physical education. This investigation is structured to develop a framework for the examination of the personal, situational and societal factors that influence the subjective interpretations recruits have of the profession and, in addition, how these serve to attract or repel recruits to or from the profession. A second purpose is to begin to assess empirically the adequacy of this theoretical framework for the subjective warrant. 
The Subjective Warrant Defined

The subjective warrant refers to an individual's perceptions of the skills and abilities necessary for entry to, and performance of work in a specific occupation. It is against these perceptions that the individual tests personal competencies, aspirations and characteristics. Lawson (in press) says of the subjective warrant

$$
\begin{aligned}
& \text { constructed on the basis of personal } \\
& \text { biography, the effects of significant others, } \\
& \text { societal influences, and direct experiences } \\
& \text { in schools it is an instrument for identity } \\
& \text { formation and self selection which is crucial } \\
& \text { to an understanding of recruitment processes } \\
& \text { in physical education. }(p .7) \text {. }
\end{aligned}
$$

Moreover, Western and Anderson (1968) suggest that in the pre-training phase of professional socialization, decisions to enter a profession are influenced by the relative prestige attributed to the profession, the individual's self concept and the relationship between these two factors. They also suggest that the visibility of the profession is important in this process, and that the perceptions developed by the individual may be based on lay conceptions of the profession that may be stereotypical and general rather than informed and accurate. Thus, it can be seen that the subjective warrant may be at odds with the realities of work in the profession. It is, however, these subjective perceptions that form the basis for the decision to enter the profession, and, as such, determine the types of individuals who are attracted to a career in physical education. Herein lies an added measure of the significance of a subjective warrant: it makes more transparent a profession's otherwise invisible attempts to announce itself to new recruits. 
Thus, it can be seen that any investigation concerned with the subjective warrant for physical education must consider the individual in relation to both personal abilities and skills, and situational and societal influences. Professions, moreover, are institutionalized entities, and therefore assumptions about institutionalization must also inform this investigation (Berger and Luckmann, 1966; Giddens, 1979). It is only by linking these factors in the framework provided by the subjective warrant that one can discover the nature of the perceptions about the profession and, ultimately, how these influence recruitment into physical education.

\section{Definition of Terms}

The terms that have been used in this study are defined in the following ways

1. PHYSICAL EDUCATION is used in two different ways in this study.

a) It is used in its more generic sense to refer to the whole spectrum of job opportunities that are available within the profession;

b) More specifically it is used to refer to the programmes of, physical education that are taught in secondary schools.

2. SPORT is used to refer to any physical activity that occurs other than school organized sport and physical education.

3. PROFESSIONAL SOCIALIZATION refers to the process by means of which individuals acquire the ideological perspectives appropriate for a 
professional role, and the knowledge, skills and sensitivities that are essential for the performance of this role.

4. RECRUITMENT is the first stage of professional socialization and represents the factors that serve to attract individuals to the profession.

5. SUBJECTIVE WARRANT is a construct that represents the perceptions an individual has of the skills and abilities necessary for entry to and performance of work in a specific occupation. 


\section{Chapter Two}

\section{LITERATURE REVIEW}

The earliest work on occupational choice stemmed from the classic psychometric work of Cattell (1890) and Yerkes (1919) in which an individual's dispositional traits (e.g. intelligence, aptitudes, personality characteristics and interests) were matched with job requirements. The task of the scientist was to objectively assess these traits in order to facilitate the job placement of individuals. In so doing, scientists interested in occupational choice assumed the role of social engineer. This work was hampered, however, by the inherent limitations in trait theory, not the least of which were its static view of behaviour and its over simplified view of occupational choice. The dynamic personal, situational and societal factors that emerged as de facto influences upon occupational choice could not find accommodation in the trait measurement approach or its parent theory.

Following this early work, investigators began to search for a more satisfactory theory of occupational choice. Their efforts may be classified and reviewed under two main headings: the general literature on occupational choice, and the literature that is specific to professional socialization. In both cases, the literature may be further sub-divided into psychological investigations and sociological investigations. In this light, the aims of this review are to synthesize the findings from this wide array of literature in order to enable the development of a framework that illuminates the subjective warrant for physical education. 


\section{The General Literature on Occupational Choice}

In view of the limitations in the trait measurement approach to occupational choice, researchers began to work towards a general theory of occupational choice by approaching the problem from a variety of different disciplinary perspectives. Occupational Choice : An Approach to a General Theory (Ginzberg, Ginzberg, Axelrad \& Herma, 1951) exemplifies this interdisciplinary approach to the problem.

Limitations could be located in this work too. Each disciplinary perspective, rather than contributing towards the development of an integrated theoretical framework, emphasized the differences that existed between them. Despite these problems, this. work remains important. It provided the stimulus for further psychological and sociological research in the area of occupational choice, research that is reviewed later in this discussion.

The resultant investigations departed from this seminal interdisciplinary approach to occupational choice in favour of a variety of single disciplinary approaches. In the latter case, attempts were made to describe and explain the process of occupational choice within the framework provided by the parent disciplinary perspective. In each case the different problems and approaches to occupational choice reflected the assumptions, priorities and interests of each discipline's researchers.

Although a variety of disciplinary perspectives were used to examine occupational choice most of the research was guided by a psychological or socio-psychological perspective. Researchers guided by this perspective 
focused upon the social and social psychological factors that affected an individual's decision to enter a particular occupation.

Psychological Research on Occupational Choice

Researchers guided by this perspective attempted to establish a theoretical framework as a basis for their empirical research. The frameworks that were proposed all represented occupational choice as a developmental process. Researchers guided by these frameworks attempted to isolate and measure the factors influencing the individual at various stages of this process.

The result of all of this research has been the development of a number of different psychological micro-theories for occupational choice. These theories stress different aspects of the developmental process of occupational choice and describe these in related but different ways. There are problems with these micro-theories that are attributable to the narrow selectivity of their focus. Researchers, in the development of these theories, have accepted and applied a specific model for their examination of the occupational choice process. This a priori acceptance and application of singular models has produced selective findings. These findings are consistent with the model being applied but are incongruous with others being used to explain the same phenomenon. Herein lies one of the difficulties of examining micro-theories for occupational choice: the self fulfilling tendency of these theories to produce findings that are supportive of their propositions leads to the development of a series of competing, often equivocal, models for the process of occupational choice. 
The developmental occupational choice research has largely been influenced by the work of Ginzberg et. al., 1951; Havinghurst, 1953; Holland, 1959; Roe, 1956; and Super, 1953. The major tenets of these theories provide a useful overview of the nature and direction of the psychological occupational choice research to date.

To return to a point made earlier, Ginzberg's (1951) interdisciplinary work both affected and stimulated subsequent psychological investigations (Howe11, Frese \& Sollie, 1977; O'Hara \& Tiedeman, 1959; and O'Hara, 1962). Ginzberg et. al. (1951) identified three developmental stages in an individual's occupational decision making process. During the first stage, the fantasy period, the child's occupational preferences are reflections of occupational sterotypes and an interest in an occupation appears to be a sufficient basis for choice. The second stage is the tentative period and lasts from the ages of around 11 to 17 . During this stage the individual's behaviour is characterized by an increasing awareness of the attributes, both personal and educational, required for entry into specific occupations. During the third and final stage, called the realistic period, the individual attempts to work out a vocational plan by synthesizing both subjective and external factors. This approach has been summarized as follows:

Ginzberg regards the socially decisive act by which one ultimately enters the world of work as the culmination of a series of sequentially ordered decisions which span a minimum of six or seven years and which usually require at least ten years for their completion. In working out his choice the individual stands in conflict between his subjective desires (i.e. psychological motives) and the demands and restrictions imposed by social and economical reality. (Borow, 1966, p. 400). 
This process is, in Ginzberg et. al.'s (1951) view, an irreversible one. The individual is assumed to move through a series of ever narrowing choices until a final decision is reached.

The major contribution of Ginzberg et. al.'s (1951) work to the study of occupational choice is in his depiction of choice as a process that begins in early childhood and extends into late adolescence. This theory has provided the impetus for research with younger children in an area that had formerly concentrated exclusively upon young adults.

Other researchers working from a developmental psychological perspective remained in the mainstream tradition of Cattell (1890) and Yerkes (1919). They were interested in examining the relationship between occupational choice and individual characteristics or traits. They emphasized, in short, the importance of individual factors, rather than external environmental factors.

For example, Roe (1956) developed a classification scheme in which she categorized occupations in relation to the nature of the work activity involved in the job and the skill and training required for performance of the work activity. Using this classification scheme as her basic framework, Roe (1956) attempted to link the psychological climate of parent child relationships in early life to occupational choice. The central tenet of this theory is that individuals will seek out occupations that are compatible with their need structures and that these structures are developed as a result of parent child relationships. There is limited empirical evidence to support Roe's (1956) theory of occupational choice. This may be attributable, in part, to the complexity of the choice process 
and the failure of this theory to account for any of the other factors that may be influential in this process. In essence, personality is only one of a variety of factors that may influence occupational choice and a framework that excludes external factors and concentrates solely on the individual is oversimplified and incomplete.

Holland's (1959) theory of occupational choice takes a broader view of this process and links personality types to different model environments. Within his typology Holland (1959) has identified six different personality types and six model environments. The six personality types are labelled as being realistic, investigative, social, enterprising, conventional and artistic. Holland (1959) assumes that all individuals fit into one of these types and when making a choice an individual will search for an environment that is compatible and consistent with their personal orientations.

Holland's (1959) theory has some important implications for research on occupational choice in physical education. Within his classification scheme Holland (1959) identifies physical educators as social types. That is, individuals attracted towards a career in physical education are depicted as having an interest in the manipulation of others by means of informing, training, developing, curing or enlightening. Holland (1959) also suggests that social types are predisposed towards occupations in which they can engage in preferred activities and competencies and those in which it is possible to display teaching behaviours to help others. Although Holland (1959) broadly classifies all physical educators as social types he makes a distinction between physical education teachers and coaches. He suggests that the personality types for both teaching and coaching, although related, involve different orientations and behaviours. It can be seen then 
that Holland (1959) makes a distinction between the roles of both teachers and coaches in physical education suggesting that each requires different orientations and will attract different types of individuals. If, as Holland (1959) asserts, there are similarities between individuals in specific occupations and that these individuals create characteristic working environments, then the effect of occupational sterotypes on occupational choice merits attention. The nature of this sterotype for physical education and its influence on the choice of the profession as an occupation is an important question that has to be considered in relation to the choice process for physical education.

Havinghurst (1953) and Super (1953) in their theories of occupational choice emphasize the relationship between developmental tasks, self concept and occupational choice. The frameworks developed by these researchers include a series of six stages through which individuals progress during their vocational development. Havinghurst (1953) and Super (1953) both believe that individuals develop an occupational identity over time, an identity that forms the basis for their occupational choice. That is, an individual develops an occupational identity through learning by observation, imitation, identification and interaction with significant others and then seeks out occupations that help to verify and preserve this identity.

To summarize the preceding psychological work on occupational choice, it is clear that these frameworks differ with respect to the emphasis that is accorded to developmental and psychological factors that influence occupational choice. Super (1953) and Havinghurst (1953) focus their attention on the processes leading to an occupational choice, whereas, Roe 
(1956) and Holland (1959) concentrate upon the products of that choice. These theories are similar, however, to the extent that they all stress the importance of the individual in the choice process.

Despite the tendency of these theoretical frameworks to highlight the individual and to down play the interaction of the individual with situational and societal factors, some important insights into occupational choice may be derived from them. The import of these theories for the development of a broader framework for occupational choice lies in two areas. They identify appropriately the process leading towards occupational choice and they identify some of the learning experiences that influence the development of an occupational identity. It would appear that individuals learn about different occupations through their observation and imitation of significant others. Therefore, occupational choice may be based on the stereotypical views of occupations that individuals gain from their interactions with, and learning from, significant others.

\section{Sociological Research on Occupational Choice}

Occupational choice has also been the focus of interest for researchers working from a sociological perspective, and Ginzberg et. al's (1951) work has been influential here as well. These researchers examine the process of choice in relation to the interactions between both individual and societal factors.

Sociological investigations of occupational choice had, prior to the work of Ginzberg et. a1. (1951), been limited to that which stood to be illuminated by a macroscopic analysis of work. The research following the work of Ginzberg et. al. (1951) marked a change in focus in sociological 
analyses of work. Occupational choice became an area of interest in its own right and researchers attempted to develop a purely sociological theory to explain the dynamics of the process leading to an occupational choice.

Socialization became the pivotal concept in the ensuing sociological framework for analysing occupational choice. Research framed by this conceptualization attempted to identify the factors, both societal and individual, that influenced this choice and, in addition, to examine the nature of the process leading to an occupational choice (Elliott, 1972; Gross, 1958; Rogoff, 1957; Theilens, 1957).

This research differed from the interdisciplinary approach to occupational choice in two significant ways. The first of these rests in the definition of the problem. Unlike the earlier work of Ginzberg et. al. (1951) there were more rigorous attempts to delinate the problem. Ginzberg et. al.'s (1951) delination of occupational choice as the range of all occupations within a given sociai structure was considered to be too general. Gross (1958) and Elliott (1972) both made the distinction between the range of all possible choices available to an individual and the actual range of choices available to the individual. The latter subsumes a much smaller range that is delimited by factors such as social class, gender, level of education, culture and family and peer influence. Gross (1958) made this distinction clear in his statement that

in short, "choice" should be examined in the context of the realistic alternatives open to the individual, his knowledge of them, and his access to them. ( $p .146$ )

This important distinction had important implications for research investigating. occupatinal choice. 
This redefinition of occupational choice led to the second significant difference in the research resulting from a sociological framework. Socialization, defined as "the processes by which people selectively acquire the values and attitudes, the interest, skilis and knowledge-in short the culture current in the groups of which they are, or seek to become members" (Merton, 1957, p. 287) assumed new importance. The process of socialization provided researchers with a framework for analysing the "realistic" alternatives open to an individual.

Once socialization became the analytical tool for the analysis of occupational choice, researchers began to view this choice as one part of the larger process of professional socialization. The resultant studies attended, in the main, to the medical and legal professions and researchers developed and used modeis of professional socialization to guide their research (Merton, 1957; Rogoff, 1957; Theilens, 1957).

\section{The Professional Socialization Literature}

Research into occupational choice as a part of the recruitment process has received very little conceptual and empirical attention in professions other than medicine and law. Professional socialization remains neglected in both the teaching profession and in physical education. It is assumed that the research on other professions provides a useful starting point for the consideration of physical education. Where there is any data from studies on physical education this will be cited but in the absence of this research it is useful to refer to the findings of investigations from medicine, law, dentistry and teaching. Wholesale application of these 
findings is not being advocated. Rather, they are to be viewed as useful guidelines for research in physical education.

Initial studies in medicine and law that addressed recruitment, investigated not only the ways in which individuals made certain choices but, also, some of the reasons why they made these particular choices. These investigations examined both the factors influencing the choice to study medicine or law and the timing of these choices (Rogoff, 1957; Theilens, 1957).

Rogoff (1957) and Theilens (1957) identify two types of choice patterns for entrants into medicine and law. They differentiate between youthful and older deciders (Rogoff) and early and late deciders (Theilens) in their studies. They found evidence to suggest that the individuals in these groups make their career choices in different ways. They found that for early and youthful deciders parental influence and encouragement (especially that of the father), the presence of, and contact with, family members who were doctors or lawyers and the educational levels of parents were all significant factors contributing towards career choice. Older or late deciders, on the other hand, attributed factors such as peer infiuence and encouragement, the presence of a role model in the profession and personal academic achievement as important influences in their decisions to enter law or medicine.

Helfrich (1975), in her research on different pathways of entry into dental school, investigated the patterns of events, situations and experiences tht categorized particular paths or routes of entry into dental school. She identified four different pathways and found evidence to 
suggest that different factors were significant in the choice of dentistry as a career, dependent upon the nature and timing of that choice. She . distinguished between individuals who made their decisions: during high school (early school deciders), during college (late school deciders), at work after high school (early work deciders) and at work after college (late work deciders). She found that the recruits in the four categories differed with respect to their social origins, interpersonal influences, college experiences and social relationships with others.

The studies by Helfrich (1975), Rogoff (1957) and Theilens (1957) are important as they mark a move from single path models for routes of entry into occupational fields to multiple path models where the passage through formal education into a profession is not always assumed to be invariant and continuous. In other words, these researchers do not assume that individuals enter professions via highly uniform pathways in which entry is mediated through a series of similar, successive, invariant steps. Rather they acknowledge that there may be other pathways leading to entry into professional schools (Becker and Struass, 1956).

These results have important implications for studies investigating the factors influencing recruitment into physical education. They suggest that the decision to enter the profession is influenced in different ways for different individuals depending on the timing and context of their decision.

Whilst granting these important contributions, these studies were not without limitations. Although these early studies were guided and framed by a view of professional socialization, investigators were not guided by any 
specific framework. Thus, in the absence of a framework to link the findings from these studies, investigations examining recruitment into the professions remain descriptive rather than explanatory.

It is in this light that Lortie's (1975) sociological analysis of school teachers and teaching was a step forward. Lortie (1975) outlined a framework for occupational choice and used it to examine the process of recruitment into the teaching profession. For his analysis of this process Lortie (1975) identifies the "recruitment resources" of a profession. These are defined as

the properties which assist an occupation in competing for manpower and talent. (Lortie, 1975, p. 26).

An individual is, in this model, attracted to an occupation as a result of the recruitment resources that are proffered to potential recruits.

Lortie (1975) identifies two types of recruitment resources, which he calls attractors and facilitators. Attractors are the comparative benefits that are offered potential recruits. These include both material benefits (money, job security and social mobility) and psychic or symbolic attractors (prestige, power and satisfaction). Facilitators are the social mechanisms that facilitate an individual's entry into an occupation or profession and these include the influence of significant others (teachers, parents, family and friends), the absence of occupational alternatives (one may fail to meet the entry requirements of other occupations) and finally, the subjective warrants of recruits. 


\section{Recruitment into the Physical Education Profession}

Lortie's (1975) model provides a useful starting point for the analysis of the recruitment process in physical education. To date, there has been very little interest in the process of recruitment, either conceptually or empirically, within physical education. Templin, Woodford and Mulling (1982) in their review of the occupational choice and anticipatory socialization literature in physical education found only four studies that have examined this process (Mulling, 1981; Pooley, 1970; Templin, 1979; and Woodford, 1977).

The research examining the recruitment process in physical education will be reviewed in order that some of the factors influencing the choice of physical education as a profession may be determined. Lortie's (1975) thematic structure provides a useful method of organizing and linking the research findings in physical education.

\section{The Interpersonal Theme}

Both the roles of teacher of physical education and coach in a school athletics programme involve extensive personal interaction with young children and adolescents. Given the people centered orientation of the profession one might expect that potential recruits would reflect such an orientation. The data from the physical education research supports this proposition. There is evidence to indicate that a major factor in recruits decisions to enter physical education is the desire to work with and help others (Pooley, 1970; Templin, 1979; Woodford, 1977). 
Pooley (1970) and Woodford (1977) both found that approxiamtely 40 percent of the entrants surveyed in their studies attributed their choice of physical education to the desire to help others. Templin (1979), found a similar trend in his data with almost 30 percent of his sample citing that the interpersonal dimension of physical education was a major factor in their decisions to enter programmes of physical education. Mulling (1981), in a survey of 21 entrants to a university physical education programme, found that 95 percent of her sample chose physical education because of the opportunities it provided for helping others. She also found that of this 95 percent 71 percent revealed a desire to work with children. This finding gains support from the data from the National Educational Association (1980-81) study on the status of the American schoolteacher. 82 percent of the practising physical education teachers surveyed entered the field as a result of their desire to work with children.

\section{The Service Theme}

Lortie (1975) also examined the attraction of teaching on the basis of service. He found that individuals who entered teaching tended to view the profession as one in which it was possible to provide a valuable service to society. There is evidence that the same feelings hold true for physical education entrants (Pooley, 1970; Templin, 1979; Woodford, 1977). Mulling (1981) also found that for 61 percent of her sample, the opportunity to provide a valuable service to society was a significant factor in their decisions to enter programmes of physical education.

The data from these investigations suggest that individuals view physical education as a profession that affords them with the opportunity 
to work with people, especially young people, and to provide a valuable service to society. Whether this is true in every case remains a question. However, these views of the profession appear to serve as important influences in the choice of physical education as a career.

\section{The Continuation Theme}

Many of the impressions, viewpoints or frames of reference recruits have of physical education are developed and modified in the light of both primary and secondary involvements in school physical education. This is suggested by the fact that Templin (1979) and Woodford (1977) found that the vast majority of recruits in their studies (almost 90 percent) enjoyed their experiences in both physical education and athletics in elementary and secondary school.

Pooley (1970), Templin (1979) and Woodford (1977) also found that recruits spent a large proportion of their leisure time in physical education or sport related activities. The data indicates that the major focus in the lives of the majority of the physical education recruits is sport. In fact, both Templin (1979) and Woodford (1977) found that 90 percent of the entrants in their studies had participated in interscholastic sport, and further, that the majority of these recruits ( 78 percent and 86 percent respectively) had been involved in coaching and teaching while attending secondary school. It would appear that for a number of individuals physical education programmes may be viewed as sport programmes. Programmes, that may, ultimately, provide a useful stepping stone en route to careers in professional sport. This view of physical education as a career contingency (Lawson, in press) reflects non-altrustic 
motives for entry into physical education programmes and must be considered in any examination of recruitment into the profession.

It would appear then that recruits in physical education programmes have extensive primary and secondary involvements in sport. They participate in interscholastic and agency sponsored sports, assume teaching and coaching roles, maintain spectator interest and read the sport related literature, all of which serve to foster an interest in both coaching and teaching as career options. The subjective warrants of these recruits seem to be greatly influenced by experiences in both physical education and sport. In addition, it appears that interest and ability in sport and physical activity form an important part of this recruitment resource.

Therefore, it would seem that individuals may experience a variety of influences that lead towards their involvement in sport and then, as a consequence of this involvement, their attitudes, values and views of the profession may be contoured further. Here then is an important conceptual and theoretical link between socialization into, and socialization via, sport. It illuminates further the subjective warrant.

\section{Ease of Entrance into Physical Education Programmes}

It has already been established that entrants into programmes of professional education in physical education view interest and ability in physical activity as important prerequisites for entry. However, factors such as the admission standards and the acadenic rigour of the programme, the years spent in training and the financial resources required to complete this training, are all factors that may be important when career choices are being made. 
There is no information on the importance of these factors for recruitment into physical education programmes or how these factors influence the recruits' decisions when making comparisons with other professional programmes. This aspect of recruitment into physical education merits attention as the nature of these entrance requirements will determine, to a large extent, the academic calibre of the individuals the profession is able to attract and retain.

The issue of programme standards leads to questions about the type of individuals who are attracted to both teaching in general and programmes in physical education in particular. Templin et. al. (1982) found evidence to show that physical education entrants generally have very mediocre records of high school academic achievement. This, coupled with the low entrance requirements of many physical education programmes, suggests that perhaps physical education is one of the few alternatives open to many early deciders and to late deciders with blocked aspirations. This proposition gains support from studies from Bookwalter (1941) and Kenyon (1965) who both found that physical education majors were inferior to other students in their performances on tests measuring intellectual aptitude. In effect, the physical education entrant may be limited in the options available in professional education as a direct result of their inability to meet the requirements of other professional programmes.

This proposition gains additional support from the findings from a nationwide investigation of the academic ability in the teaching force in the United States (Vance \& Schlechty, 1982). It was found that teaching not only failed to attract the most able college and university graduates but attracted a disproportionate share of the least able graduates. Vance and 
Schlechty (1982) attribute this to the lack of rigour in the entrance requirements of most teacher education programmes and the concomitant lack of respect and status of the profession. These findings have serious implications for recruitment into the whole teaching profession, including physical education. These implications are clearly spelled out by Vance and Schlechty (1982) when they state that

the fact that teaching is unattractive to the more
academically able and disproportionately attractive to
the less able creates a public relations problem for
the teaching occupation and probably serves to
discourage many potentially competent teachers from
pursuing careers in this field. $(p .26)$.

It can be seen then that the comparative ease of entry into programmes of physical education may serve to attract recruits who have relatively poor academic records. This may be the only option available in higher education for these recruits as the entrance requirements for other professional programmes are more stringent and require higher levels of academic achievement. This has important implications for the subjective warrants of physical education recruits. The lack of rigour in the selection of entrants for professional education seems to imply that academic excellence is not an important aspect of the profession. By undermining this aspect of physical education programmes one might expect recruits to view the profession as almost totally skill and performance oriented. Physical education, in this view, is playing games and learning how to teach them to others.

There is some evidence that this is the basis for an occupational sterotype. Hendry and Whiting (1972), for example, found that physical educators were viewed as representing body rather than mind. This image of 
the profession, although stereotypical and at odds with the realities of work, forms the basis for the career choices of many physical education recruits. This image may serve to attract certain types of individuals to the profession, while failing to attract others who may be equally suited to a career in physical education. Herein lies the importance of the subjective warrant. It provides an individual with a certain view of the profession and, as such, determines the types of individuals attracted to and, by the same token, repelled from a career in physical education.

\section{Socializing Agents as Facilitators}

The research in physical education has concentrated upon the influences of specific individuals in the lives of recruits, namely, teachers, coaches, parents and family members. The data from these studies has - largely been obtained from new entrants to physical education programmes who have generally all made the decision to enter these programmes while still at high school. The significant others for these early deciders have been found to be teachers, coaches and immediate family.

The influence of a role model such as a teacher or coach may be either positive or negative. In the former case the recruit enters the profession with the intent of emulating the model. The desire to teach or coach just like a particular coach or teacher who is viewed as an exemplary model is an important attractor to the profession for many recruits. For the recruit with a negative role model, the desire is to enter the profession in order to foster change. Templin (1979), found examples of both of these orientations in the recruits in his study, that is those who were committed 
to preservation of the system and those who believed strongly in the need for change.

Data from the studies by Pooley (1970), Templin (1979), Seagrave (1980) and Woodford (1977) suggest that for the majority of recruits, individuals in their roles as coaches, rather than as teachers, of physical education were most influential in their decisions to enter the physical education profession. For example, Pooley (1970) found that 41 percent of his sample felt that their coaches were most influential in their decisions to enter physical education, whereas, only 28 percent of his sample attributed their entries to the influence of teachers of physical education. Seagrave (1980) found that, when given the choice between coaching and teaching, most of his respondents chose coaching, specifically, coaching the sports in which they were actively involved as athletes. The data from the Templin (1979) and Woodford (1977) studies did not distinguish between physical education teachers and coaches. Nevertheless, this data supports the fact that both physical education teachers and coaches are viewed by many entrants as being the most influential factor in their decisions to enter programmes of physical education.

The data from these studies also reveals several differences between male and female entrants on the extent to which physical education teachers and coaches were influential in their career decisions. Pooley (1970) found that 58 percent of the males in his sample felt that their coaches were most influential in their decisions, whereas, only 12 percent of the males attributed the same importance to their teachers of physical education. For the female entrants in his sample the physical education teacher was most influential for 48 percent, whereas, coaches were only felt to be most 
influential by 23 percent. These trends were also found in the data from Templin's (1979) and Woodford's (1977) studies, which would appear to imply that for many males entry into physical education is mediated by the influence of a coach but, for females, this influence is largely attributable to teachers of physical education.

Although gender differences in perceptions of occupations and occupational choice has not been the subject of much examination in physical education, research investigating the perceptions of and characteristics of male and female physical education students (Bain and Wendt, in press; Landers, 1970) indicate that there are significant differences between them. This finding is also supported by the more generic occupational choice research literature (McLure and Piel, 1978; O'Bryant, Durrett and Pennebaker, 1978) where there is considerable evidence to show that males and females view occupations in different ways and often make vocational choices on the basis of different information and influences.

Therefore, it is important when investigating the subjective warrants of potential physical education recruits to have an awareness of gender differences and develop a theoretical framework that accounts for these differences.

These findings have other important implications for recruitment into physical education. One might expect that individuals entering programmes that are designed specifically towards the education of teachers of physical education would cite teachers rather than coaches as most influential in their career decisions. The fact that this is not the case 
for a considerable number of entrants to these programmes suggests 'that these recruits have subjective warrants that do not view professional education as only education for teaching. It is possible, on the other hand, that many recruits have not made a distinction between coaching and teaching and may view them as two interrelated working roles. Bain and Wendt (in press) obtained evidence to support this view. They found that prospective physical educators perceived the roles of teacher and coach as requiring similar charactertistics and abilities. In addition, they found that 58 percent of the females and 45 percent of the males in their sample displayed an equal committment to both teaching and coaching. Thus, despite documented role conflict, this shows how the subjective warrant can be at odds with realities.

Findings from studies in medicine, law, dentistry and teaching have all shown that family members exert considerable influence on career choice (Helfrich, 1975; Lortie, 1975; Rogoff, 1957; Theilens, 1957). This influence is also apparent, but to a lesser extent, in the data from the studies on physiçal education recruits.

Pooley (1970), Templin (1979) and Woodford (1977) all found evidence to suggest that their entrants felt that their fathers and/or mothers exerted a significant influence in their decisions to enter programmes of physical education. The data from these studies varied to the extent that they found gender differences in the degree of parental influence and only Woodford (1977) found that his entrants reported that siblings were influential in their career choices. Pooley (1970) found that 19 percent of the males in his sample and 8 percent of the females cited their fathers as the most influential individuals in their choice of physical education as a career. 
He also found that 12 percent of the females cited their mothers as most influential in this choice. Woodford (1977) found minimal differences in parental influence across gender. He found that 18 percent of his sample cited their fathers as most important and 8 percent cited their mothers as most important. In addition, 10 percent of his sample cited an older brother as being most influential. Templin (1979) found that 16 percent of his sample felt that their fathers were most influential in their career choices and 10 percent cited their mothers in this role.

This data suggests that the subjective warrants of recruits are influenced by the significant others in their lives. These individuals seem primarily to be coaches, teachers of physical education, fathers, mothers and siblings, particularly older brothers. It is probable that the extent of this influence varies, in both degree and kind, between recruits and in relation to the other factors that make up their subjective warrants.

\section{Implications of this Research for the Subjective Warrant for Physical Education}

There are certain limitations in the studies on occupational choice in physical education. First, and most important, Templin et. al. (1982), in their analysis of occupational choice and the anticipatory socialization process in physical education, adopt in toto Lortie's (1975) model for occupational choice. Within this framework, the subjective warrant for physical education is viewed as only one of a number of recruitment resources that serve to facilitate entry into the profession. On the other hand, the subjective warrant emerges in this analyses as a broader construct than Lortie (1975) first envisaged. For example, in the light of 
the analyses of anticipatory socialization provided by Pooley $(1972,1975)$ and Western and Anderson (1968) and, Lawson's (in press) discussion of recruitment processes in physical education, the subjective warrant is the perceptual frame through which recruits view the profession. It provides a vision that is shaped and developed as a result of all the attractors and facilitators that Lortie (1975) identifies as recruitment resources. The subjective warrant, in this study, provides the key to an understanding of the process of recruitment in the physical education profession. When viewed in this way the subjective warrant provides a construct in which it is possible to link all of the factors that influence the process of recruitment into the profession. Therefore, there are inherent limitations associated with the wholesale application of Lortie's (1975) model to physical education.

It should also be noted that all of the research in this area, to date, has been conducted on individuals who have already entered physical education programmes. No research has been conducted on high school students who are considering physical education as a possible career option. It is important to gain an insight into the subjective warrants of these individuals before they enter programmes of physical education. An understanding of the formation, content and impact of the subjective warrant on the visions of the profession held by all types of recruits is essential to a complete understanding of the whole process of professional socialization.

It has become apparent during this review that there is no broadly based, comprehensive theoretical framework to guide research on recruitment into the profession. Despite the fact that researchers from different 
disciplinary perspectives have investigated the concept of occupational choice, the tendency has been to focus on one specific aspect of the process to the exclusion of others. The ensuing summary reveals that this is, indeed, the case.

\section{Summary of the Occupational Choice Research Findings}

\section{Psychological Research Findings}

Researchers guided by a psychological perspective have concentrated, primarily, upon the relationship between individual factors and occupational choice. This research has led to some important findings. These will be presented in point form for clarity and ease of understanding:

(1) Occupational choice is a process that starts in early childhood and extends to adulthood.

(2) Individuals make occupational choices in relation to their subjective assessments of personal abilities and needs and the characteristics, demands and skills required of various occupations.

(3) Impressions that individuals gain about occupations tend to be learned as a result of the interaction and learning from significant others. These impressions are often stereotypical in nature.

(4) Males and females view occupations in different ways and often make choices on the basis of different information. 
Sociological Research Findings

Sociological research has been focused on situational and societal factors and their relationships to occupational choice. Researchers guided by this perspective have found that:

(1) Occupational choice is not, realistically, the range of all possible vocations available to an individual but, is a small range determined by a variety of situational and societal factors. Occupational choice delimited in this way is the actual range of available options for any individual.

(2) This range is determined by socio-economic status, gender, educational levels of father and mother, economic variables and cultural values and expectations.

(3) When placed in the broader framework of professional socialization, the process of occupational choice can be linked to the concept of socialization. Within this framework occupational choice becomes one part of the first stage of professional socialization, recruitment into the professions.

\section{Findings from the Professional Socialization Literature}

The major contribution of this literature has been the development of a three stage model for professional socialization that links recruitment into the professions with professional education and the performance of work. It has been found that: 
(1) There are multiple routes of entry into the professions. Factors influencing the decision to enter a profession are related to the timing and context of the decision. Early and late deciders may enter a profession for different reasons and possess quite different views of the profession they have chosen to enter.

(2) An individual's view of the profession is contoured by an interaction of the individual, situational and societal factors outlined in the previous two sub-headings.

(3) Research on recruitment into physical education has highlighted a variety of factors that are influential in the choice of physical education as a career. This decision is influenced by, participatory experiences in sport and physical education, significant others, stereotypes of the profession, attitudes and values about the nature of the work in the profession, ease of entry into professional programmes of education, gender, perceptions of personal abilities and skills and, those required for the role of physical educator or coach and cultural background and socio-economic status.

(4) The individual appears to be first socialized into the profession and then through participation and experiences in sport and physical education, socialized via this involvement.

Although it is now clear that the subjective warrant varies among individuals and results from the interaction of individual, situational and societal factors, there is not yet an adequate theoretical framework for it. The findings that have been summarized, nevertheless, stand as 'bricks' from which a theoretical edifice may be constructed (Forscher, 1963). 
Chapter Three

\section{THE BEGINNING OF A THEORETICAL FRAMEWORK}

The review of the literature on occupational choice has revealed that there is no comprehensive theoretical framework to guide the research on recruitment into the physical education profession. There is a need for such a framework that links findings from the related literature. This framework should provide the basis for a refined examination of the subjective warrant for physical education. Nevertheless, it is assumed that any such framework will be modified in the light of the empirical findings gained from the subsequent study. This is characteristic of the development of grounded theory (Glaser and Strauss, 1975).

It is possible on the basis of the findings highlighted in the review of literature to identify some of the factors that constitute and contribute to and mark the beginnings of a theoretical framework for the subjective warrant for physical education. These factors are presented in Table 1 .

Insert Table 1 About Here 
Table 1

The Factors Influencing and Individual's Subjective

Warrant for Physical Education

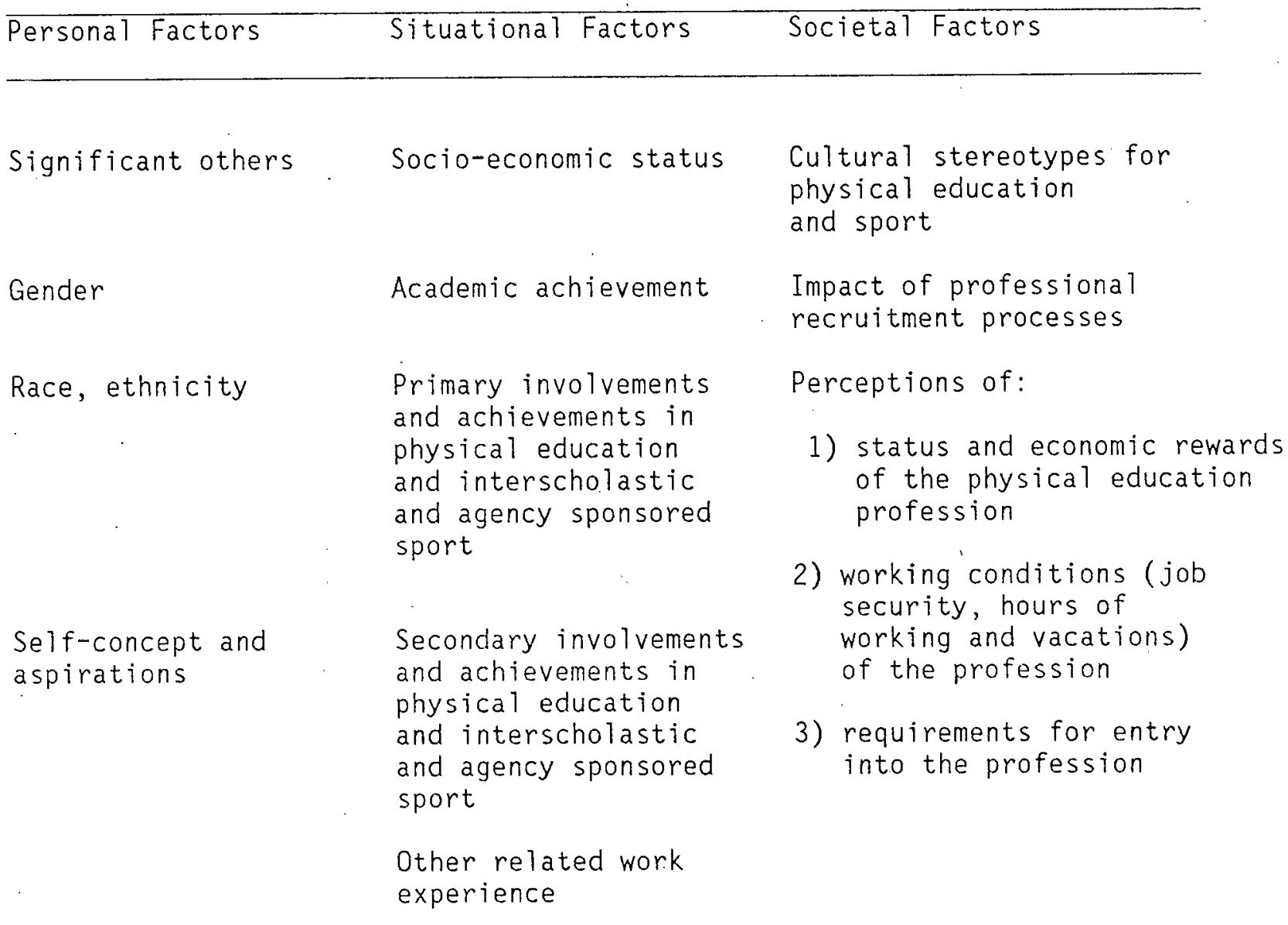


It is important to recognize that the factors in Table 1 are not mutually exclusive. They may interact both within and between the conceptual categories in which they have been organized.

It can be seen that Table 1 provides a synthesis of the sociological, psychological and professional socialization literature and applies them directly to physical education. From this table it is possible to derive a number of hypotheses for the subjective warrant. These hypotheses form the basis for the empirical research in this study.

\section{Hypotheses}

\section{Attraction to a Career in Physical Education}

(1) Students will be attracted to a career in physical education because they perceive that:

a) it provides a continuous association with sport and physical activity;

b) it involves working with people;

c) it offers good working conditions;

d) it constitutes a valuable service to society.

(2) Students who are attracted to a career in physical education will:

a) have extensive primary and secondary involvement in sport and physical education;

b) be the top students in their physical education classes; 
c) perceive themselves to be high achievers in interscholastic sport.

The Decision to. Enter the Physical Education Profession

(1) Male recruits who choose physical education careers will:

a) cite the influences of their coaches and fathers as important;

b) have mean or below mean grade point averages in relation to other university entrants.

(2) Female recruits who choose physical education careers will:

a) cite the influences of their physical education teachers, mothers and older brothers as important;

b) have greater grade point averages than male physical education recruits but similar grade point averages in comparison to other university entrants;

c) do so as a result of blocked aspirations.

(3) Recruits oriented to teaching more than coaching will:.

a) have limited involvement and achievement in interscholastic sport;

b) cite the influence of their physical education teachers as important;

c) possess custodial orientations if they enjoy and are high achievers in their primary involvements in physical education; 
d) possess innovative orientations if they are high achievers but do not enjoy their primary involvements in physical education.

(4) Recruits oriented to coaching more than teaching will:

a) desire to coach the sports in which they are involved;

b) view physical education as a career contingency;

c) view physical skill as a primary pre-requisite for entry to professional education programmes;

d) possess custodial rather than innovative orientations.

It is possible, on the basis of the information from the review of literature and the research hypotheses, to formulate hypothetical profiles for individuals who are attracted to, or have decided upon, a career in physical education. These profiles are presented in Table 2

Insert Table 2 About Here

The information in the profiles has been organized into two categories: recruit's background characteristics and perceptions. This distinction allows both a comparison of the different types of individuals who may be attracted to a career in physical education and an examination of the subjective warrants of these recruits. These profiles provide a starting point for the analysis of the data in this study because they facilitate a refined examination of the subjective warrant for physical education. 
Predicted Profiles of Male and Female Physical Education Recruits

Types of Recruits

\section{BACKGROUND CHARACTERISTICS}

1) Extensive primary involvements in sport and physical activity

2) Extensive secondary involvements in sport and physical activity

3) Top students in physical education classes

4) High achievers in sport and physical activity

5) Mean or below mean grade point averages

6) Mean or above mean grade point averages

PERCEPTIONS

1) View profession as providing opportunities to:

i) work with people sociation with sport and physical acitivity

i i) provide a valuable service to society

iv) work in good conditions

2) Orientation to teaching rather than coaching

3) orientation to coaching rather than teaching

4) Custodial orientation to role

5) Innovative orientation to role

6) View profession as skill oriented

7) Role models are

i) fathers

i i) mothers

ii i) siblings

iv) teachers of physical education

v) coaches

$$
\begin{gathered}
x \\
x \\
x \\
x \\
x
\end{gathered}
$$

$\begin{array}{ll}x & x \\ x & x \\ x & x\end{array}$




\section{Chapter Four}

\section{METHOD}

Subjects: A total of 40 grade 10-12 high school students served as subjects. The subjects were enrolled in six secondary schools in the Vancouver school board. The subjects were selected from Eric Hanber, Killarney, Kitsilano, Lord Byng, Point Grey and Templeton secondary schools. Six categories served as the basis for the classification of subjects from these schools. These categories were:

1) Male students who:

a) have decided to pursue a career in physical education (decided);

b) are attracted to a career in physical education (attracted);

c) are high achievers in sport and physical education but have decided against a career in physical education (not attracted).

2) Female students who:

a) have decided to pursue a career in physical education (decided);

b) are attracted to a career in physical education (attracted);

c) are high achievers in sport and physical education but have decided against a career in physical education (not attracted).

Subjects were identified by physical education teachers and school career counselling staff. Every attempt was made to question equal numbers 


$$
-43-
$$

of male and female subjects for each category. The numbers of subjects questioned in each of the six categories is presented in Table 3

Insert Table 3 About Here

Instrument: Open and close ended questions in five categories were developed from the theoretical framework. The five categories were: general background information, general school information, nature of sport involvements, attraction to the profession (career plans) and the decision to enter the profession. These questions were pilot tested on eight (four female and four male) University of British Columbia physicai education undergraduate and graduate students. Half of the subjects were given the questions in the form of a.written questionnaire and the other half were asked to give verbal responses to the questions in an interview situation. All subjects were questioned individually and asked to comment on the clarity, length and complexity of the wording of the questions. 
Table 3

Number of Subjects Tested in Each Category by Sex

Sex Category Males Females Sum of Males and Females

$\begin{array}{llll}\text { Decided } & 9 & 7 & 16 \\ \text { Attracted } & 7 & 5 & 12 \\ \text { Not Attracted } & 6 & 6 & 12\end{array}$


The results from the pilot test revealed two specific findings. It was found that:

1) The closed, forced choice questions directed the subjects' answers in specific ways. In these questions the tendency was for the subjects to guess at the desired response and choose that as their answer. The open ended questions, on the other hand, resulted in subjects having to articulate their own responses and reflected more accurate accounts of their perceptions of the physical education profession.

2) The subjects who were given the written questionnaire rather than the interview felt happier with their answers to the open ended questions. The interview subjects had problems giving clear, accurate answers to the questions and all expressed a desire to be allowed to have time to think about and write down their responses.

These findings from the pilot work led to the development of an extensive written questionnaire, with primarily open ended questions, that was further pilot tested on five (three male, two female) high school grade 11 students. The results from this second pilot led to minor changes in the wording and ordering of some of the questions. The final questionnaire, after two pilot tests, consisted of 28 open ended questions that required written responses from the subjects; this questionnaire appears as Appendix A.

\section{Procedure}

Permission to conduct the study was sought and granted from the University of British Columbia and the Vancouver school board (see Appendix 
B). Nine schools from the Vancouver school board were selected as potential schools from which subjects could be drawn. This selection was based on data from a survey of the 1982-83 University of British Columbia first year undergraduate physical education students that revealed the high schools attended by these students.

A letter of explanation and a request for permission to conduct the study was sent to the principals of each of the nine selected secondary schools (see Appendix C). The principals were contacted by telephone one week after the dispatch of the letters and arrangements were made, where necessary, to visit the physical education department heads of consenting schools (six of the nine schools). The physical education principals were give a copy of the questionnaire and any questions or concerns about the study were discussed. Subjects from each school were identified by the physical education staff and/or careers counsellors and appointments were set up for questioning.

Individuals interested in participation in the study were given a verbal explanation of the nature and purpose of the study and the time committment that was involved as a subject. Students interested in participating in the study were then administered the questionnaire by the researcher. Subjects were given the questionnaire both individually and in small groups, they were asked to read the introduction to the questionnaire and to feel free to ask any questions about the study. Following this, subjects were told that the data in the study would be treated confidentially and, in addition, it was explained that they were free to withdraw from the study at any time without fear of jeopardizing their academic grades or class standing. Subjects were asked to read the 
questions in the questionnaire carefully and to answer them to the best of their ability. Each individual spent approximately 60 minutes completing and checking their responses. Subjects were thanked when they had completed their responses and were given an opportunity to ask any further questions.

After completion of all of the administering of questionnaires, school principals and physical education staff were contacted and thanked for their interest, time and cooperation in the study. A copy of the findings from the study were sent to each of the schools.

\section{Constraints}

There are several limitations to this study. First, the time constraints imposed by high school principals on the release of students for questioning and the extensive nature of the questionnaire necessitated limiting the sample size to 40 subjects. Second, school principals expressed concern over the time involved in the release of subjects on an individual basis for questioning, which resulted in the use of a written questionnaire and questioning in small groups, rather than individually. Finally, the written questionnaire did not allow probing or the follow up that is possible when a subject is interviewed. This problem was met by keeping questions simple and, in addition, by asking subjects for written explanations for 211 of their answers. 


\section{Chapter Five}

\section{RESULTS AND DISCUSSION}

\section{General Background Characteristics}

\section{Primary Involvement in Sport and Physical Education}

A11 of the subjects had some form of primary involvement in sport or physical education. 95 percent of the males in the study participated in both interscholastic sport and organized sport or physical activity other than their school sport. Of the females in the study, 72 percent participated in school organized sport and 94 percent participated in sport and physical activity other than school sport.

This data supports the physical education research findings by Pooley (1970), Templin (1979) and Woodford (1977), which suggest that individuals attracted to physical education careers have extensive primary involvements in sport and physical education.

\section{Secondary Involvement in Sport and Physical Education}

90 percent of the subjects had secondary involvements in sport and physical education. 86 percent of the males and 94 percent of the females were involved in coaching, teaching, umpiring or refereeing or had held paying jobs related to sport or physical education. The majority of subjects, 67 percent, were involved in coaching or teaching, 22 percent had umpiring or refereeing experience and 22 percent had held part time jobs related to sport and physical education. 
These findings further support the data from the research in physical education (Pooley, 1970; Templin, 1979; and Woodford, 1977) in which physical education recruits were found to have extensive secondary involvements in sport and physical education.

Time Committment to Sport and Physical Activity

For both the males and females attracted to or decided upon a career in physical education, 79 percent spent 30 or more hours per week in activities involving sport or physical education. For the male and female subjects who had decided against a career in physical education only 25 percent devoted this amount of time to sport or physical education.

This finding supports the proposition that individuals attracted to a career in physical education have sport or physical activity as the major focus in their lives (Pooley, 1970; Templin, 1979; and Woodford, 1977). For the majority of those individuals decided against a career in physical education, this proposition is not supported and for these individuals sport may be only one of the interests in their lives.

Family Participation in Sport and Physical Activity

Al1 of the subjects had parents and/or siblings that participated in sport or physical activity. 85 percent of subjects had parents that participated in sport and 93 percent reported that their siblings were involved in participation in sport and physical activity. Thus, the majority of subjects have extensive primary and secondary involvements in sport and physical education and, in addition, have families that participate in sport and physical activity. 
Rank in Physical Education Class

The male subjects all ranked themselves in the top 15 percent of their physical education classes, with 82 percent rating themselves in the top 5 percent and 18 percent in the top 15 percent of the class. 72 percent of the female subjects rated themselves in the top 15 percent of their physical education classes. 33 percent rated themselves in the top 5 percent, 39 percent in the top 6-15 percent, 22 percent in the top 20-25 percent and 6 percent in the lower 50 percent of their classes.

These differences in ratings for males and females may be attributable, in part, to the fact that many of the female subjects were in co-educational physical education classes and rated themselves against both the males and females in the class. The answer to this question can only be resolved if, in future research, subjects are asked to rate themselves against the whole class, against the males only in the class, and against the females only in the class.

\section{Grade Point Average}

40 percent of subjects had $A$ or $B$ grade point averages (g.p.a.). The remaining 60 percent had $C$ or $C+$ g.p.a.'s. 37 percent of male subjects attracted to, or decided upon and 33 percent of males decided against a career in physical education had A or B g.p.a.'s. For the females in the study, 58 percent attracted to or decided upon and 16 percent of those decided against a career in physical education had A or B g.p.a.'s.

These results support, in part, Templin et. al's (1982) findings that the majority of physical education entrants have mediocre records of 
academic achievement. However, this is only true for the male subjects in this sample and not for the females, the majority of whom had above average g.p.a.'s. This finding may be attributable to the fact that for females with blocked aspirations physical education is viewed as an attractive career (McLure and Pie1, 1978; O'Bryant et. a1. 1978).

\section{Summary of General Background Characteristics}

An analysis of the subjects' background characteristics reveals that they share some common characteristics. The majority of subjects have extensive primary and secondary involvements in sport and physical education, have sport or physical activity as the main focus in their lives and have parents and siblings that participate in sport and physical activity. Male and female subjects differed with respect to their grade point averages and self ratings of rank in physical education classes. Overal1, this data lends support to Holland's (1959) theory that occupations tend to attract individuals who share similar characteristics.

\section{Perceptions of the Profession}

Analysis of the nature of the perceptions of the subjects attracted to and decided upon a career in physical education revealed that there exists both a dominant and several non-dominant perceptions of the nature of the work that exists and the knowledge and skills required for this work in the physical education profession. This finding is consistent with the work of Helfrich (1975), Rogoff (1957) and Theilens (1957) who all found evidence to suggest that there are multiple paths of entry into a profession, and 
the decision to enter a profession is influenced in different ways for different individuals.

The results will be discussed in relation to these different perceptions of the physical education profession. It is these perceptions that represent the subjects' subjective warrants for physical education. First, the most frequently expressed, or dominant, view of the subjects attracted to and decided upon a physical education career will be presented. Second, four distinctive, non-dominant views of the profession will be discussed and, finally, the perceptions of the subjects who have decided against a career in physical education will be examined.

\section{The Dominant View of the Profession}

68 percent of all of the subjects attracted to or decided upon a career in physical education shared similar perceptions of the profession. 64 percent of the females and 75 percent of the males in this category had similar subjective warrants for physical education.

\section{Attraction to the Profession}

This group of subjects were attracted to careers in physical education because they loved sport, enjoyed working with and teaching children and sought a good working atmosphere and environment. For 84 percent of these subjects their love of sport was the most important reason for their attraction to the profession. The remaining 16 percent cited the desire to teach and work with children as most important.

This data supports the findings by Lortie (1975), Mulling (1981), Pooley (1970), Templin (1979) and Woodford (1977) in which the opportunity 
to work with children and the ability to maintain a continuous association with sport through physical education were found to be important attractors to the teaching and physical education professions. These perceptions appear to make up an important part of this subjective warrant for physical education.

\section{Significant Others}

The individuals perceived by subjects as influential in their attraction to a physical education career were themselves, mothers, fathers, siblings, peers, teachers of physical education and coaches. This supports the proposition that the significant others for physical education recruits are primarily physical education teachers, coaches and immediate family (Pooley, 1970; Templin, 1979 and Woodford, 1977).

The most influential individual in this choice was perceived by 47 percent of subjects to be themselves. 11 percent cited siblings, 11 percent their fathers, 11 percent their teachers of physical education and 4 percent viewed their coaches in this role. This data does not support the proposition that male and female recruits differ in the significant others they perceive as important (Templin, 1979; Woodford, 1977). Thus, although significant others appear to exert an influence upon subjects' subjective warrants this influence seems to be similar for both male and female recruits. 
Perceptions of the Nature of the Work of Physical Education Professionals

\section{Role preferences}

89 percent of subjects in this group stated a preference for a combined teaching and coaching job. The remaining 11 percent preferred a teaching job only. These choices were similar to both male and female subjects, 83 percent of females and 91 percent of males chose a job that combined teaching and coaching. This data does not support Seagrave's (1980) findings that the majority of physical education recruits chose coaching, rather than teaching, as their job preference. It does, however, lend support to Bain and Wendt's (in press) finding that almost half of their subjects displayed an equal committment to both teaching and coaching.

Comparison of Role Requirements for Teachers of Physical Education and Coaches

Subjects perceived both the roles of physical education teacher and coach as similar. Both male and female subjects emphasized that physical education teachers and coaches should have an understanding of human anatomy and physiology and their relationships to physical activity and have the ability to explain and communicate the skills being taught to a variety of different individuals of varying abilities and skills. In addition, successfuil teachers and coaches were perceived to have good interpersonal skills, leadership qualities, devotion and dedication to their job and the ability to control and discipline their students and athletes. 
Teachers of physical education, specifically, were viewed as requiring basic knowledge about a wide variety of sports and, in addition, the ability to demonstrate the basic skills in these sports. Coaches, on the other hand, were seen as requiring specialized knowledge about, and experience as a high level performer in, the sport they are coaching.

This data suggests that the majority of individuals attracted to or decided upon a physical education career view the roles of teacher and coach as requiring similar knowledge and skills. This finding gives support to the proposition that recruits' subjective warrants for physical education may be at odds with realities (Bain and Wendt, in press). A career in physical education is perceived as being primarily skill oriented and involved with playing games and learning how to teach them to others. The subjective warrants of these recruits reflect a stereotypical image of the profession (Hendry and Whiting, 1972) and this appears to serve as an important attractor to the profession for many individuals.

\section{Role Orientations}

58 percent of subjects ( 43 percent of females and 66 percent of males) expressed custodial orientations, that is the desire to reproduce their school physical education programmes. For the 42 percent of subjects expressing innovative orientations, that is the wish to initiate changes, (57 percent of females and 44 percent of males) to these programmes, the desire was to ensure that more emphasis was placed on teaching individuals higher levels of skilled performance. Thus these changes were ones of degree rather than kind; subjects basically wanted more of what already existed but at a higher level. 
The data for subjects' orientations to interscholastic sport programmes showed different trends. 79 percent of subjects ( 85 percent of females and 75 percent of males) reflected custodial orientations. These subjects felt that their school sport programmes were good and worthy of duplication. The 21 percent of subjects who expressed innovative orientations felt that programmes should be expanded to provide more sports at a competitive level. Again, this reflects changes in degree rather than kind. Thus, the data supports Templin's (1979) findings that recruits entering physical education reflect primarily custodial and to a lesser extent innovative orientations to these roles.

\section{Non-Dominant Perceptions of the Profession}

32 percent of subjects reflected different perceptions and orientations to careers in physical education. These will be presented as four separate cases.

Case 1: Coaching as a Career in Physical Education

Three subjects (two male and one female) were attracted to careers in physical education because of their love of sport and their perceptions of the opportunities that exist in the profession for individuals to maintain a high level of involvement in sport through coaching. For these individuals the most important attractor to the profession was the opportunity that a physical education career provided for individuals to remain physically active in high level sport. All of these subjects perceived themselves to be the most important individuals in their decisions to enter the profession. They stated that the motivation and 
desire to succeed at high levels of competition gave them the confidence to pursue physical education careers.

All of the subjects stated a preference for a coaching job only and they viewed the knowledge and skill requirements for teaching and coaching as related but different. Physical education teachers were seen as requiring teaching, communication and interpersonal skills, coupled with a basic knowledge of different activities, minor injuries and first aid. Coaches, on the other hand, were perceived as requiring dedication, organizational and leadership skills, an extensive specialized knowledge of the factors influencing high levels of performance and the experience as a high level performer in the sport being coached. It was also stressed that individuals had to be good disciplinarians and able to control and command respect from their athletes if they were to be successful coaches.

The subjects reflected custodial orientations to their interscholastic sport programmes and the female subject expressed a desire to change her school physical education programme. She felt that physical education classes should be stratified on the basis of skill in order that more able performers can be challenged and taught higher levels of skill.

For all of these subjects teaching physical education is viewed as a career contingency (Lawson, in press). In other words, teaching is viewed as the best way of gaining access to opportunities for a full time career in coaching.

Case 2: Physical Education to Sports Medicine 
Three of the female subjects in the study were attracted to a career in physical education. because of their belief in the importance of an education for health through the study of sport and physical education. A career in physical education is seen as attractive to these subjects because it will allow them to combine knowledge about science and physical activity and working with young people. The most important attractor to the profession for these individuals was their love of sport and their own belief in the importance of an education about health through physical activity.

Significant others for these subjects were, parents, physical education teachers, coaches and sports medicine doctor and chiropractor. For two of the subjects their physical education teachers and coaches were the most influential individuals in their career choice. For the third subject, her sports medicine doctor and chiropractor assumed this role.

Al1 three subjects stated a preference for a combined coaching and teaching job as this was seen as one possible way of gaining direct experience before entering the medical profession. The knowledge and skill requirements for both teaching and coaching were viewed as similar by all of the three subjects. They stressed that both teachers of physical education and coaches required an understanding of human anatomy and physiology and their relationships to physical activity, as well as a specialized knowledge of health, biology and the prevention and treatment of sports injuries. It was also stressed that coaches and teachers should keep up to date with any changes in the knowledge of the field and apply these insights to their teaching and coaching. 
Two of the subjects reflected innovative orientations to their physical education and interscholastic sport programmes. They believed in the need for a change in emphasis of the goals of these programmes towards more individualized, quality learning stressing participation rather than exclusion.

For these individuals a career in physical education is viewed as being more than just teaching or coaching. They view the study of physical education as a necessary first step towards the development of knowledge about sport and physical activity necessary for a career in sports medicine, where scientific and medical knowledge can be combined with physical education to promote health through physical activity.

Case 3: Physical Education as the Planning and Implementation of Programmes for Physical Activity

Two subjects (one male and one female) were attracted to careers in physical education as a result of the challenge, interest and responsibility to be derived from. the planning and implementation of programmes that serve to encourage participation in physical activity.

Both of these individuals experienced discouragement from their parents in relation to careers in physical education and viewed themselves as the most important individuals in their decisions to enter the profession. Both subjects had also worked with individuals involved in the planning and implementation of recreation programmes and cited this experience as an important influence in their attraction to the profession. 
The male subject stated a preference for a combined coaching and teaching job as this would allow him to have an impact in both of these areas of physical education. The female subject, on the other hand, expressed the desire to be more than a teacher or instructor and wanted involvement in the design and planning of recreational programmes. Both subjects viewed teaching and coaching as requiring similar knowledge and skills and these perceptions were the same as those of the individuals in the dominant group. Interpersonal skills, teaching ability, discipline, confidence and the ability to demonstrate basic skills (teachers) and more complex skills (coaches) were viewed as important.

Both subjects reflected innovative orientations to their physical education and school sport programmes. They stressed the importance of the setting up of goals that emphasized cooperation, enjoyment and involvement for individuals of all abilities and levels of skill.

Physical education, for these subjects, is not viewed as only offering careers in teaching and coaching. Although teaching and coaching are viewed as primarily skill oriented, the desire of these individuals is to change the system. By becoming involved in the planning and implementation of programmes that facilitate greater. involvement in physical activity these subjects view a career in the profession as a challenging and interesting one.

Case 4: Early Decider but Late Entrant into the Physical Education Profession

The final non-dominant case was expressed by one male subject who shared the same view of the profession as the dominant group in all but one 
way. For this individual attraction to the profession was based on his love of sport and the desire to teach children, with the former being the most important. This subject viewed a combined teaching and coaching job as ideal and did not differentiate between the knowledge and skills required for both teaching and coaching. This subject also reflected a custodial orientation to both his school physical education and interscholastic sports programmes, both of which were considered to be well run and worthy of duplication. The difference, however, between this subject and those in the dominant group lies in his view of the opportunities for employment as a physical educator. Teaching and coaching opportunities are viewed as extremely limited in both their availability and salary range. To resolve this problem the subject has decided to pursue $a$ business career before entering the physical education profession. This individual shows clearly that there are alternative routes of entry into physical education and all recruits need not necessarily enter physical education directly from high school (Helfrich, 1975; Rogoff, 1957; and Theilens, 1957).

\section{Perceptions of the Individuals who have Decided}

Against a Career in Physical Education

Of the 12 subjects who had decided against a career in physical education. 91 percent cited the fact that they did not want to teach as the primary reason for this decision. The other 8 percent (one female) had not considered a career in physical education because she had always wanted to pursue a medical career. 
These subjective warrants reflect the dominant view of the physical education profession. Subjects' perceptions of a lack of alternative job opportunities in the profession, the low pay and the limited life span of teachers of physical education constitute an important part of this subjective warrant. It is this subjective warrant for physical education that is pivotal in these subjects decisions not to pursue careers in physical education. In essence, although the majority of these subjects enjoy their sports participation and rate themselves in the top 15 percent of their physical education classes, it is their subjective warrants for physical education that serve to turn them away from rather than attract them to a career in the profession.

\section{Summary of Results}

\section{General Findings}

1. It was found that the majority of subjects in the study shared similar background characteristics but differed with respect to their subjective warrants for the profession.

2. The majority of subjects had similar subjective warrants for the profession but, in addition, four non-dominant views of the profession were expressed by a small majority of subjects.

3. Subjects who decided against a career in physical education held uniform subjective warrants for physical education. These subjective warrants also paralled those held by the majority of individuals attracted to or decided upon a career in physical education. 


\section{Specific Findings}

\section{General Background Characteristics}

It was found that the majority of subjects in the study:

1. Had extensive primary and secondary involvements in sport and physical education.

2. Had parents and siblings who participated in sport and physical acitivity.

3. Spent 30 or more hours a week in sport related activity.

For the Males in the study, the majority:

1. Ranked themselves in the top 5 percent of their physical education classes.

2. Had average ( $C$ to $C+$ ) grade point averages.

For the females in the study, the majority:

1. Ranked themselves in the top 15 percent of their physical education classes.

2. Had above average ( $A$ to $B$ ) grade point averages.

\section{Subjective Warrants for Physical Education}

\section{Dominant Perceptions}

The majority of subjects attracted to or decided upon a career in physical education: 
1. Were attracted to the profession because it was viewed as providing a continuous association with sport, the opportunity to work with and teach children and as possessing a good working atmosphere.

2. Were influenced by their own perceptions of the profession, coaches, teachers of physical education, members of their immediate families and peers.

3. Viewed the roles of teaching and coaching as requiring the same knowledge and skills.

4. Possessed both custodial and innovative orientations. Those who had innovative orientations desired to make changes in degree rather than $k$ ind.

5. Possessed similar views of the profession regardless of gender.

6. Viewed the profession as skill oriented and concerned with learning how to play games and teach them to others.

\section{Non-Dominant Perceptions}

Subjects oriented to coaching

1. Viewed the profession as primarily concerned with teaching high levels of skilled performance.

2. Were attracted to the profession as a result of the desire to maintain a high level of participation in sport.

3. Were influenced primarily by their own perceptions but also by coaches and teachers of physical education.

4. Viewed teaching as a career contingency.

5. Viewed the roles of teacher and coach as requiring different knowledge and skills. 
6. Reflected custodial orientations.

Subjects oriented to sports medicine

1. Were attracted to the profession because it provided more career opportunities than just teaching and coaching.

2. Were influenced by teachers of physical education, coaches and doctors specializing in sports medicine.

3. Viewed knowledge about physical education as a necessary pre-requisite for entry into sports medicine.

4. Viewed the roles of teacher and coach as similar and requiring the application of scientific knowledge to sport and physical activity.

5. Possessed innovative orientations.

Subjects oriented towards the planning of sport programmes

1. Viewed the profession as more than teaching and coaching.

2. Were attracted by the challenge, interest and responsibility associated with the job.

3. Were influenced by their own perceptions and work experiences in the planning of recreational programmes.

4. Possessed innovative orientations.

Subject as an early decider but late entrant to a career in physical education

1. Shared a similar perception of the profession as those subjects in the dominant group but viewed teaching opportunities to be limited in both availability and salary range. 
2. Perceived that entry to the profession would be best after the achievement of a secure income through a career in business. 


\section{Chapter Six}

\section{CONCLUSIONS}

The physical education profession appears to attract individuals who share a number of similar background characteristics, namely extensive primary and secondary involvements in sport and physical education. These background characteristics provide a necessary but insufficient explanation of the choice of a physical education career for many individuals. It is the nature of an individual's subjective perceptions about the profession their subjective warrant, that forms the basis for an explanation of this career choice:

The subjective warrant for physical education provides the key to an understanding of recruitment into the physical education profession. It links together the factors that serve to both attract individuals to and facilitate their entries into the profession. It is these individuals' perceptions of the nature of the knowledge, skills and sensitivities required for entry to and work in the physical education profession that are pivotal in their career choices. These subjective warrants serve to either attract or repel individuals to or from the profession.

There exists, for a majority of individuals, a dominant subjective warrant for physical education. This subjective warrant is one in which a career in physical education is viewed exclusively as one of teaching and coaching. The existence of this dominant subjective warrant for physical education reflects the institutionalized nature of the profession. A way of 
viewing a career in physical education has become the way. In essence, the physical education profession is announcing itself to a majority of individuals as offering only a career in teaching and coaching. This dominant, institutionalized subjective warrant reflects a stereotypical view of the nature of the work in the profession. Yet, despite being at odds with the realities of work and the nature of the career opportunities available in the profession, this subjective warrant primarily serves to attract individuals oriented to teaching and coaching and repells others who, although not oriented to teaching, may be equally well suited to alternative careers in physical education.

There are, however, a small minority of individuals who have subjective warrants that differ from the dominant perception of the profession. The existence of these non-dominant subjective warrants attest to the fact that the socialization experiences that lead towards the development of the dominant perceptions of the profession, although powerful, are not automatic. The individuals possessing non-dominant subjective warrants were attracted to careers in physical education in order to foster improvement and change. The profession was attractive to this minority of individuals because they perceived that there was a challenge to be derived from initiating change.

This study has shown that the physical education profession announces itself to the majority of individuals in one way. That is, as offering a career in teaching and coaching. The other alternatives available to individuals seeking careers in physical education are only apparent to a minority of individuals. This minority all have subjective warrants in 
which teaching is viewed as one of a number of career options in physical education rather than the only option.

\section{Implications of this research}

If the physical education profession continues to be perceived by a majority of individuals as offering only careers in teaching and coaching it will persist in attracting primarily those individuals oriented to teaching and coaching and who possess custodial orientations to this role. There is a real danger in physical education that the profession will recruit primarily those individuals who wish perpetuate and reproduce the system, which will further institutionalize and reinforce the dominant perception of the profession announced to potential recruits. This stasis within the profession will make more difficult the professions ability to cope with change and, as such, may result in deprofessionalization. The physical education profession can begin to address this potential problem by examining the ways in which it announces itself to potential recruits. If efforts are made to understand the importance and impact of the subjective warrant on recruitment into the profession then physical education will not continue to lose out on the silent competition for recruits (Lortie, 1975).

\section{Suggestions for Further Research}

The results from this study show that it is important to investigate the nature of individuals' subjective warrants for physical education prior to their entries into programmes of professional education. An 
investigation of individuals' subjective warrants while they are in schools provides one with an insight into the factors that serve to attract and facilitate individuals' entries into physical education and, in addition, enables a refined examination of the perceptions of those individuals who have rejected careers in physical education.

The subjective warrant provides one with a theoretical framework that guides research on recruitment in physical education; research that can begin with children and adolescents rather than individuals who have already made their career choices. An identification of the ways in which the physical education profession announces itself to potential recruits through an examination of the subjective warrants of these recruits marks a change in focus of the research on recruitement in physical education.

On the basis of the results from this study it is evident that there are a number of questions that must be answered in order to further refine the theoretical framework for the subjective warrant. For example, it is important to identify the nature of the relationships between individuals' perceptions of the profession and different types of physical education and sport programmes. In this light, an investigation of the relationships between the subjective warrants of teachers of physical education, school physical education programmes, curriculum models for physical education and students' subjective warrants merits attention. An examination of the relationships between these factors may pave the way towards a greater insight into the work of teachers of physical education and the impact of this work on students in physical education classes. 
It is also important to begin to investigate some of the reasons for the differences in the academic grade point averages for male and female recruits. An examination of socio-economic status and its relationship to blocked aspirations are important factors that must be considered when investigating career choice.

Further researh in this area must also consider an in-depth study of those individuals with non-dominant subjective warrants. Case studies of these individuals' may make possible a greater understanding of the ways in which an individual's perceptions are socialized and the impact of these socialization experiences in sport and physical education on the subjective warrant.

Thus, research examining the subjective warrant for physical education has the potential to provide researchers with a framework that allows the examination of individuals' perceptions before they enter programmes of professional education, when they are enrolled in these programmes and when they enter the workforce. The subjective warrant has, then, the potential to allow an enlightened perspective not only on recruitment into physical education but on the impact of profession education, the work of teaching in physical education, role orientations of teachers and coaches, curriculum models and models for work. The subjective warrant stands to provide an understanding of the whole process of professional socialization and the work of teachers of physical education. 


\section{BIBLIOGRAPHY}

Anderson, D.S., \& Western, J.S. Notes on a study of professional socialization. Australian and New Zealand Journal of Sociology, April $1967,3(1), 67-71$.

Becker, H.S., Geer, B., Hughes, E.C., \& Strauss, A.L. Boys in White. Chicago: University of Chicago Press, 1961.

Becker, H.S., \& Strauss, A.L. Careers, personality and adult socialization. American Journal of Sociology, November 1956, 62, 253-263.

Berger, P.L., \& Luckmann, T. The social construction of reality. New York: Doubleday, 1966.

Bookwalter, K.W. Are high schools over emphasizing athletics? The Physical Educator, 1941, 1, 179-80.

Borow, H. Development of occupational motives and roles In L.W. Hoffman \& M.L. Hoffman (Eds) Review of child development research. Vol... 11. New York: Russell Sage Foundation, 1966, 373-422.

Catte11, J.M. Mental tests and measurements. Mind 1890, 15, 373-381.

Crites, J.D. A comprehensive model of career development in early adulthood. Journal of Vocational Behavior, 1976, 9, 105-118. 
Coulson, M.A., Keil, E.T., Riddell, D.S. \& Strauss, J.S. Towards a sociological theory of occupational choice: A critique. Sociological Review, November, 1967, 15(2), 301-310.

Elliott, P. The sociology of the professions. London: MacMilian Press, 1972.

Englander, M.E. A psychological analysis of vocational choice: Teaching. Journal of Counselling Psychology, 1960, 7(4), 257-264.

Ford, J., \& Box, S. Sociological theory and occupational choice. Sociological Review, November 1967, 15(2), 287-300.

Forscher, B.K. Chaos in the brickyard. Science, October 18, 1963, 142, 3590.

Giddens, A. Central problems in social theory: Action, structure and contradiction in social analysis. Berkley: University of California Press, 1979.

Ginzberg, E., Ginzberg, S.W., Axelrad, S., \& Herma, J.L. Occupational Choice: An approach to general theory. New York: Columbia University Press, 1951.

Glaser, B.G., \& Strauss, A.L. The discovery of grounded theory: Strategies for qualitative research. Chicago: Aldine, 1975.

Greenhaus, J.H., \& Simon, W.E. Self esteem, career salience and the choice of an ideal occupation. Journal of Vocational Behavior, 1976, 8 , 51-58. 
Groos, E. Work and society. New York: Thomas Y. Crowell Co, 1958.

Hart, D.H., Rayner, K., \& Christensen, E.R. Planning, preparation, and chance in occupational entry. Journal of Vocational Behavior, 1971, 1, $279-285$.

Havinghurst, R.J. Human development and education. New York: Longmans, Green, 1953.

Hawley, P. What women think men think: Does it affect their career choice. Journal of Counselling Psychology, 1971, 18, 193-199.

Helfrich, M.L. Pathways into professional school. Sociology of Work and Occuptations, May $1975,2(2)$.

Hendry, L.B: Survival in a marginal role: The professional identity of the physical education teacher. British Journal of Sociology, 1975, 26, $465-476$

Hendry, L.B., \& Whiting, H.T.A. General course and specialist physical education student characteristics. Educational Research, 1972, 14, $152-156$

Holland, J.L. A theory of vocational choice. Journal of Counselling Psychology, $1959,6,35-45$.

Holland, J.L. Making Vocational choices: A theory of careers. Englewood Cliffs: Prentice Hall, 1973. 
Hollander, M.A., \& Parker, H.J. Occupational stereotypes and self descriptions: The relationship to vocational choice. Journal of Vocational Behavior, 1972, 2, 57-65.

Holzner, B., \& Marx, J.H. Knowledge application: The knowledge system in society. Massachusetts: Allyn and Bacon, 1979.

Howel1, F.M., \& Frese, W. Making life plans: Race, gender and career decisions. Washington: University Press of America, 1982.

Howe11, F.M., Frese, W., \& Sollie, C.R. Ginzberg's theory of occupational choice: A reanalysis of increasing realism. Journal of Vocational Behavior, $1977,11,332-346$.

Hulmstron, V.L., \& Beach, L.R. Subjective expected utility and career preferences. Organizational Behavior and Human Performance, $1973, \underline{10}$, 201-207.

Jones, D.M., Hansen, J.C., \& Putnam, B.A. Relationship of self concept and vocational maturity to vocational preferences of adolescents. Journal of Vocational Behavior, 1976, 8, 31-40.

Kenyon, G.S. Certain psychosocial. and cultural characteristics unique to prospective teachers of physical education. The Research Quarterly, $1965,36,1,105-112$.

Landers, D. Psychological feminity and the prospective female physical educator. The Research quarterly, 1970, 41(2), 165-170.

Lawson, H.A. Toward a model for teacher socialization in physical education Journal of Teaching Physical Education, (in press). 
Lawson, H.A., Paradigms for research on teaching and teachers. Paper presented at C.I.C. Big Ten Body of Knowledge Symposium, Indiana, November 1982 .

Lortie, D.C. Schoolteacher: A sociological study. Chicago: The University of Chicago Press, 1975.

McArthur, J. Teacher socialization: The first five years. The Alberta Journal of Educational Research, 1979, 25(4), 264-274.

McLure, G.T., \& Puil, E. College bound girls and science careers: Perceptions and barriers and facilitating factors. Journal of Vocational Behavior, $1978,12,172-183$.

McPherson, B.D. Socialization into and through sport involvement. In G.R.F. Luschen, and G.H. Sage (Eds) Handbook of Social science of sport. Champaign, Illinois: Stipes Publishing Co., 1981.

Merton, R.K., Reader, G.G., \& Kendal, P.L. (Eds) The Student physician. Boston: Harvard Univeristy Press, 1957.

Miles, M.B., Qualitative data as an attractive nuisance: The problems of analysis. Administrative Science Quarterly, December 1979, 24, 590-601.

Mills, C.W. The sociological imagination. New York: Oxford University Press, 1959.

Musgrave, P.W. Towards a sociological theory of occupational choice. Sociological Review, March 1967, 15(1), 33-42. 
Mulling, $C$. An Investigation of selected factors contributing to the desocialization of the physical education major. Unpublished Masters Thesis, Purdue University, 1981.

O'Bryant, S.L., Durrett, M.E., \& Pennebaker, J.W. Students ratings of occupational dimensions of traditionally male and traditionally female occupations. Journal of Vocational Behaviour, 1978, 12, 292-304.

O'Hara, R.P., and Teideman, D.V. The vocational self-concept in adolescence. Journal of Counselling Psychology, 1959, 6, 292-301.

O'Hara, P.R. The roots of career. Elementary School Journal, 1962, 62, $277-280$.

Pooley, J. The professional socialization of physical education students in the United States and England. Unpublished Docotors Dissertation Univeristy of Wisconsin, 1970.

Pooley, J. Professional socialization: A model of the pre-training phase application to physical education students. Quest, $1972,18,57-66$.

Pooley, J. The professional socialization of physical education students in the United States and England. International Review of Sport Sociology, $1975,3-4,97-107$.

Roe, A. The psychology of occupations. New York: Wiley, 1956.

Roe, A. Early determinants of vocational choice. Journal of Counselling Psychology, 1957, 4, 212-217. 
Rogoff, N. The decision to study medicine. In R.K. Merton et. a1. (eds) The Student Physician. Massachuchetts: Harvard Univeristy Press, 1957.

Roth, J., Rizek, S., \& Daniels, A. Current state of the sociology of occupations. Sociology Quarterly, 1973, 14, 309-333.

Seagrave, J.0. Role preferences among prospective physical education teachers/coaches. In Virginia Crafts (ed) Proceedings national association for physical education in higher education, Vol. II, Champaign: Human Kinetics, 1981.

Slocum, W.L. Occupational careers. Chicago: Aldene, 1966.

Spector, M., \& Kitsuse, J. Constructing social problems Menlo Park: Cummings Publishing Co., 1977.

Super, D.E. A theory of vocational development. American Psychologist, $1953,8,185-190$.

Susman, G., \& Evered, R. An assessment of the scientific merits of action research. Administrative Science Quarterly, 1978, 23, 582-603.

Templin, T.J., Woodford, R., \& Mulling, C. On becoming a physical educator: Occupational choice and the anticipatory socialization process. Quest, $1982,34(2), 119-133$.

Theilens, $W$. Some comparisons of entrants to medical and law school. In R.K. Merton et. al. (Eds) The student physician. Massachusetts: Harvard University Press, 1957. 
Vance, V., and Schlechty, P.C. The distribution of academic ability in the teaching force: Policy implications. Phi Delta Kappan, September 1982, $22-27$

Walsh, W.B., Howard, P.R., O'Brien, W.F., Santa-Maris, M.L., \& Edmondson, C.J. Consistant occupational preference and satisfaction self concept, self acceptance and vocational maturity. Journal of Vocational Behaviour, $1973,3,453-463$.

Western, J.S. and Anderson, D.S. Education and professional socialization. The Australian and New Zealand Journal of Sociology, 1968, 4, 91-106.

Woodford, R. The socialization of Freshman Physical Education Majors into Role Orientations in Physical Education. Unpublished Doctor's dissertation. University of New Mexico, 1977.

Yerkes, R.M. Report of the psychology committee of the national research council. Psychological Review, 1919, 26, 83-149.

Yin, R. The case study as a serious research strategy. Knowledge creation diffusion and utilization, $1981,3(1), 97-114$. 
APPENDIX A

\section{QUESTIONNAIRE}

The purpose of this study is to examine some of the factors that influence the choice of physical education as a career. It is hoped that by examining these factors it will be possible to obtain a more accurate, complete understanding of the reasons why individuals choose to enter the physical education profession. The following questions are related to your career choice. Please read the questions carefully and write your answers in the space provided.

For example, in the following question if your answer was yes you would check the yes response and then move on to answer questions 1a), b), etc. If your answer was no then you would check the no response and then move on to the next question, question 2 .

\section{Sample question}

1. Do you play basketbal1?
Yes
a) how long have you been playing
No
b) what team do you play for 
Questions

General Background Information

Sex

Grade

School

1) How old are you

2) What is your fathers occupation

mothers occupation

3) How many older brothers do you have

- younger brothers do you have

4) How many older sisters do you have

younger sisters do you have

5) Has your mother ever participated in any sport or physical activity?

Yes

No

b) For each of these activities what was/is her

level of participation?

Sport

Level of participation 
5) cont'd

6) Has your father ever participated in any sport of physical activity?

Yes

a) What did/does he do

No

b) For each of these activities what was/is his level of participation?

Sport

Level of participation

7) Do any of your brothers or sisters participate in any sport of physical activity?

Yes

a) What did/do they do

No

b) For each of these activities what was/is

their level of participation?

Sport Brother or Sister Level of participation 
7) cont'd $^{\prime}$

General School Information

1) What subjects/courses are you taking this year?

What is your favorite subject?

Why?

3) What is your overall. grade point average for these subjects?

4) Have you ever been to see the school counsellors for information about possible career choices?

Yes a Did you find this helpful in making your
No career choice Nos No
b) If yes, in what ways?


5) Does your school have a careers programme?

Yes

No

b) Has is helped you to make a career choice

Yes

No

c) If yes, in what ways?

6) Have you ever used the choices career programme to obtain information about career choices?

Yes

a) What careers did the programme suggest that

No might be suitable for you?

b) Did this help you to make a career choice? Yes No

c) If yes, in what ways 
6) cont'd

7) Do you have a future teachers class or club in your school?

Yes

No

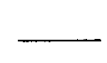

a) Have you ever taken this course or been involved

$$
\text { with the club? Yes }
$$

No

b) If yes, what did you do in this class/club

c) Did this help you to make a decision about a possible career in teaching Yes No

d) If yes, in what ways

\section{Attraction to the Profession}

\section{A. Nature of Sport Involvements}

1) Does your school have a recreation sport program (intramurals)?

Yes

No

b) If yes, in what sports a) Do you participate in this programme Yes No

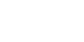


c) If no, why not

2) Do you participate in any school teams that play against other schools (inter-scholastic sport)?

Yes

a) What team(s) do you play in?

No

b) For each of these teams please provide the following information
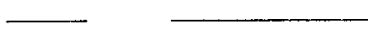

-

3) Thinking of all of the individuals in your physical education class where would you rank yourself in terms of achievement and skill

Top $5 \%$ Top $6-15 \%$ Top $16-25 \%$

Top $26-50 \%$ Lower $50 \%$

4) Do you participate in any sport or physical activity outside your school sport? 
Yes

a) What do you do

No

b) For each of the activities please provide the following information

\begin{tabular}{|c|c|}
\hline sport & $\begin{array}{l}\text { Involvement } \\
\text { Competitive or }\end{array}$ \\
\hline
\end{tabular}

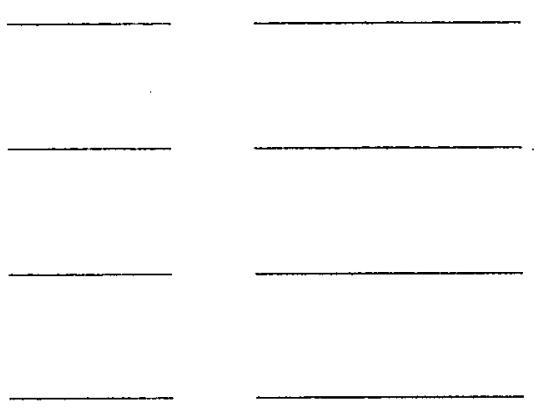

5) For each of the sports that you are participating in how would you rate yourself, on a scale of 1 to 10 , as a performer $(10=$ excellent performer, 5 = average performer, 1 = poor performer) .

Sport

Rating

Sport

Rating

6) Do you have any involvements in sport or physical activity other than your participation as a player? 
Yes

No

b) In what sports or activities

c) How did you become involved

d) How long have you been involved for

7) If you consider all of your sporting activities, how many hours (approximately)

do you spend in one week: a) practicing with the team

b) practicing alone

c) conditioning/training

d) playing

e) coaching/teaching

f) spectating

g) watching it on t.v.

h) reading about 
7) $\operatorname{cont}^{\prime} d$

i) physical education class time

j) other (specify)

8) Have your ever done any volunteer work that is related to sport or physical activity

Yes

No

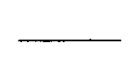

b) How did you become involved

a) What was/is it

c) Did/do you enjoy it Yes

No

d) If yes, in what ways

e) If no, why not

9) Have you ever worked in a job that is related to sport or physical activity?

Yes

a) What was it

No

b) When did you do it 
9) cont'd
c) Did you enjoy it
Yes
No

d) If yes, why

e) If no, why not

B. Career Plans

1) Do you plan to go to college or university

Yes

No

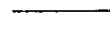

a) Where do you plan to go

b) What faculty do you plan to enter

c) Why have you chosen this college/university

d) What do you plan to do

2) Do you know what career you plan to pursue? Yes

No

3) If yes, what is it

why did you make this choice 
3) cont'd

4) If no, what careers are you still considering

5) Have you ever at any time or are you presently considering a career in physical education. Yes__ No

6) If yes, what attracted you to this career

7) If no, a) why have you never considered a career in physical education?

b) Why do you think individuals may decide against a career in physical education

Thank you for your cooperation in filling in this questionnaire. If you have any questions please feel free to ask. 


\section{Decision to Enter The Profession}

1) Do you have any friends or relatives who are involved in sport or physical activity? (eg. teaching, coaching, administration etc.)

Yes

No

Friends

Relatives specify

b) what do they do

2) Which individuals have been most influential in your decision to enter the physical education profession

3) Of all of these individuals who has been the most influential

In what ways

4) When you finish your physical education programme at university what do you plan to do? 
5) If you had a choice of

a) a coaching job only

b) a teaching job only

c) a combined teaching and coaching job

d) non of the above

a) What would you choose

b) Why

c) What do you see this job as involving

6) What qualities do you think you must possess to be good at the job you chose in 5a)

7) What do you think an individual has to know to be a

a) Teacher of physical education 
b) Coach

8) What do you think an individual has to be able to do to be a

a) Teacher of physical education

b) Coach

9) Think back to your physical education classes. What did you learn?

10) If you were given an opportunity to design and teach a school physical education programme, would you i) model the programme on your school programme

ii) design a completely different programme with different goals 
a) Why did you make this choice

b) If you chose $i i)$, what would your new goals be

11) If you had the opportunity to design and coach a school interschools athletics programme, would you i) model your programme on your school programme

ii) design a completely different programme with different goals

a) Why did you make this choice

b) If you chose the second option, what would your new goals be 
12) a) What are the most important reasons for your choice of a career in physical’ education

b). If you chose the second option, what would your new goals be

13) When did you decide to enter the physical education profession

14) Have you ever considered any other professions or occupations

Yes

a) what were they

No

b) Why did you chose physical education

15) If you could choose any profession and be sure of gaining entry into it a) what would you choose 
b) why

THANK YOU VERY MUCH FOR YOUR TIME AND COOPERATION IN FILLING OUT THIS QUESTIONNAIRE 